\title{
Perform Thermal Analysis on the Deep Grove Ball Bearing for Different Materials to Enhance the Thermal Performance
}

\author{
Vinay Kumar Shukla \\ M.Tech Scholar \\ Thermal Engineering \\ Truba Institute of \\ Engineering \& \\ Information Technology \\ Bhopal, MP, India \\ vs830711@gmail.com
}

\author{
Prof. Jeetendra Mishra \\ Assistant Professor \\ Thermal Engineering \\ Truba Institute of \\ Engineering \& Information \\ Technology, \\ Bhopal, MP, India
}

\author{
Prof. Amit Singh \\ Assistant Professor \\ Thermal Engineering \\ Truba Institute of \\ Engineering \& \\ Information Technology \\ Bhopal, MP, India
}

\author{
Prof Shamir Daniel \\ Associate Professor \\ Thermal Engineering \\ Truba Institute of Engineering \& \\ Information Technology, \\ Bhopal, MP, India
}

\begin{abstract}
The main objective of the present work to perform thermal analysis on the deep grove ball bearing for different materials to enhance the thermal performance, for that three dimensional CAD model of deep groove ball bearing of 110 $\mathrm{mm}$ outer diameter, $70 \mathrm{~mm}$ inner diameter of rolling balls diameter of $9.525 \mathrm{~mm}$ with 12 balls have been used to perform thermal analysis for the stainless steel, high carbon chromium steel, metal matrix (Ti-6Al-4 V-12TiC), GCr15 steel, silicon nitride (Si3N4) and Zirconium dioxide ( $\mathrm{ZrO2}$ ). Results show that heat flux in chromium steel is $4.3 \%$ more than stainless steel, titanium ally $25.34 \%$ more than chromium steel, CCr15 63.015\% more than titanium alloy, metal matrix (Ti-6Al-4 V-12TiC) $28.97 \%$ more than GCr15 steel and zirconium dioxide $\&$ silicon nitride gives 1.57 times more than metal matrix and other materials. It has been also observed that zirconium dioxide $\&$ silicon nitride gives 6.07 times total heat flux more than stainless steel, 5.78 times more than chromium steel, 4.41 times more than titanium alloy, 2.32 times more than $\mathrm{CCr} 15$ and 1.57 times more than metal matrix. Hence zirconium dioxide \& silicon nitride have better thermal performance.
\end{abstract}

Keywords: Ball-Bearing, Rollers, Optimizing Techniques; Rolling Contact Bearings; Substances Utilized.

\section{INTRODUCTION}

The conditions anti-friction bearing, anti-friction bearing, and bearing all refer to a type of bearing wherein the high overhead is transferred via rolling contact instead of sliding motion. The preliminary friction in a bearing is roughly twice that of the sliding friction, but it is insignificant when compared to the original friction of a plain bearing. The frictional characteristics of a bearing are affected by the functioning load, speed, and lubricant viscosity. Although it is likely difficult to relate to a roller bearing as a "roller bearing," the term is widely used in the industry. The research of bearings varies from the research of other subject areas across several ways for mechanical developers, because the bearings they specify have been already developed. The bearing developer is expected to face with the challenge of developing a set of elements that constitute a bearing: such components should fit into a space with appropriate dimensions, assistance a load to particular qualities, and, eventually, have a good service existence once functioned under the specific circumstances. As a result, bearing experts must take into account factors like fatigue loading, friction, heat, resistance to corrosion, kinematics, material parameters, lubrication, machine tool tolerances, subassemblies, consumption, as well as expense.

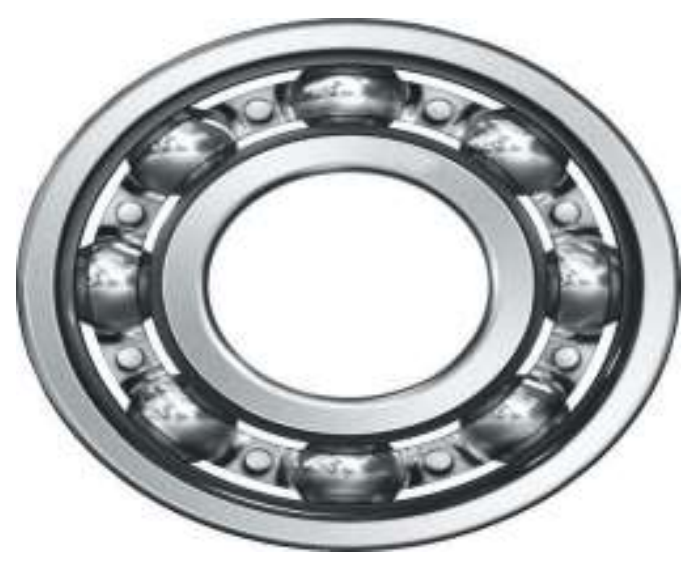

Figure 1 Ball bearing

The four important components of a bearing are depicted in the diagram. It is made up of an inner race installed on the shaft or 
journal, and an exterior race performed by the housing or casing. As can be seen in Figure, there seem to be balls or rollers around between the internal and external races. A number of balls or rollers have been employed, and retainers keep them at the proper distances so they don't collide. The retainers are typically 2-part thin strips that are constructed after the balls have indeed been adequately positioned. For light loads, ball bearings are employed, and for heavier workloads, roller bearings are employed.

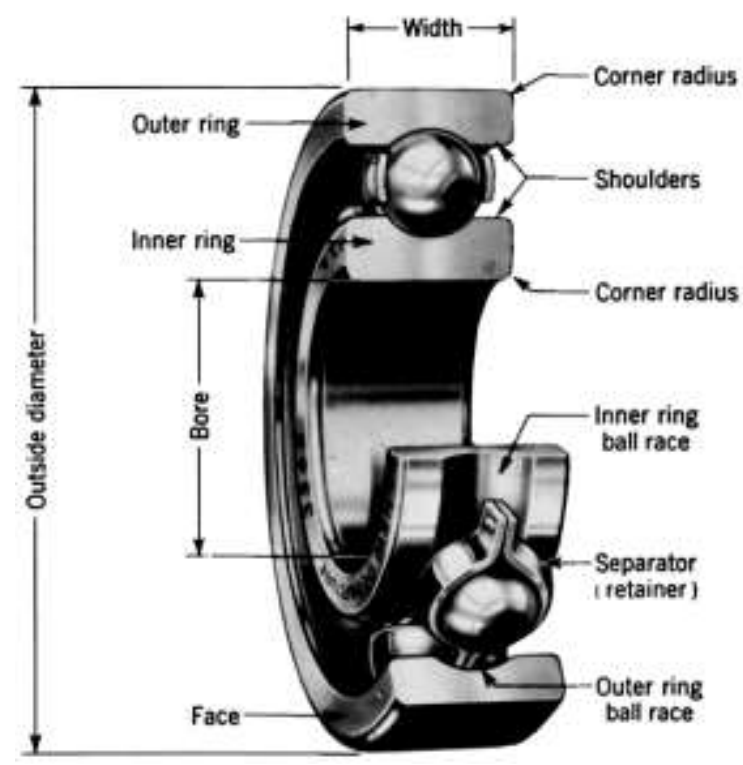

Figure 2 Nomenclature of a ball bearing

\section{LITERATURE REVIEW}

Dinh Sy Truong et al. (2021) [1] Thermal impacts on bearing stiffness as well as, as a result, the natural frequencies of a highspeed spindle scheme are addressed in this section. Friction torque at the connections among the raceways as well as the balls of angular contact ball bearings generates thermal energy. Six bearings as well as a built-in motor were used as heating systems in our investigational spindle framework. Depending on the thermal variables, five-by-five bearing stiffness matrices have always been calculated. To calculating frequency response mathematically, the stiffness matrices were being employed as inputs for a FEM generated in the ANSYS Workbench surroundings, wherein the bearings were designed to simulate as bushing joints. The simulated findings demonstrate that as the temperature rose, the $3 \mathrm{rd}$ natural frequencies reduced, which was consistent well with test.

Miaomiao Li et al. (2021) [2] Currently, empirical heat transfer coefficients are used to determine thermal performance in oilair-lubricated angular-contact ball bearings. This method has flaws, including modelling the exact lubrication flow field and disregarding internal bearing ring temperature distribution. To analyse the flow field as well as temperature field, this paper has proposed a Computational fluid dynamic steady-state analytical framework of oil-air-lubricated angular-contact ball bearings relying on fluid-solid conjugate heat exchange. To ensure that the computation study findings were correct, a temperature increase test of oil-air-lubricated angular-contact ball bearings was performed. The impacts of lubrication variables, operational requirements, and rolling component materials on the temperature emerge features of oil-air-lubricated angularcontact ball bearings have been investigated utilising a fluidsolid conjugate heat transfer steady-state analytical model.

V. Choubey \& S. Agarwal (2021) [3] Engineering is a field of applied science that necessitates creativity. Mechanical engineering, in specific, is a metaphor for progress in fabrication, development, and architecture. Software program for mechanical systems has reached a modern level as a result of technological advancements. This program is designed to use CATIA and ANSYS, two mechanical design software programmes, to virtually generate, visualize, determine, inspect, and notify on the heat transfer of simple ball bearings utilising three separate substances. It then needs to be compared the outcomes for the three substances and draws conclusions about which substance would be best for a ball bearing in order to improve effectiveness.

Clement Rabreau et al. (2019) [4] In machining, spindle dynamics is a major concern. To explain and control the complexities of spindles at high speeds, thermo-mechanical models of spindles must be established. Because it is a boundary condition of the shaft, a precise bearing stiffness method is necessary. Bearing models rely on kinematics hypotheses at the ball-race contact points, and bearings also perform an essential role in heat production in the spindle. The goal of this article is to investigate how these kinematics hypotheses affect bearing heat generation. The various kinematic hypotheses available in the literature are introduced and applied in the bearing friction model. Bearing dynamics experiments are run, and contact force as well as torque at ball-race contacts are compared.

Xianwen Zhou et al. (2018) [5] A temperature distribution measurement system predicated on fibre Bragg grating for bearing internal and external rings is suggested, and a bearing testing rig has been formed to monitor the temperature of bearing rings at numerous points. The bearing's temperature as well as allocation are then investigated using a method to calculate that is continuous with the experimental analysis. The temperature distribution of the internal and outernal rings is also examined with respect to the applied load and rotating speed. The findings show that the inner ring has a higher temperature than the outer ring, and that the circular temperature variance of the static ring is heavily influenced by the radial load as well as rotating speed. 
Karni Venkatesh \& Kona Ram Prasad (2017) [7] The heat flow as well as other variables in a bearing were studied using the Finite Element Method (FEM). SOLIDWORKS was used to create the system model. The assessment was carried out to investigate the bearing's thermal dissipation. All of the variables were entered into ANSYS when the model was extracted. Modifying the characteristics yielded the temperature distributions in the bearing. A institutional analysis was carried out, and the bearing's deformation at multiple points was estimated.

Ke Yan et al. (2016) [8] The quasi-dynamic framework of ball bearing was supported by the six-DOF balls, five-DOF internal ring, and three-DOF enclosure. The model's motions and heat production were again fed into a detailed simulation analysis for cage experimental investigation on heat. The oil-air flow sequence within the bearing cavity, as well as the effect of cage variables including pocket shape, guidance methodologies, and clearing, on bearing cage heat removal effectiveness, were all studied. The findings show that appropriate cage parameters are important for air-oil circulation and thermal dissipation within the bearing cavity at ultra high rotor speed.

\section{METHODOLOGY}

The variables of geometries in [Miaomiao Li et al. 2021] including the radius of the bearing is $55 \mathrm{~mm}$, the internal radius of the bearing is $53 \mathrm{~mm}$, the radius of rolling balls is $4.7625 \mathrm{~mm}$, and the number of balls is 12 were used to create a three-dimensional computer aided design model of a deep groove ball bearing.

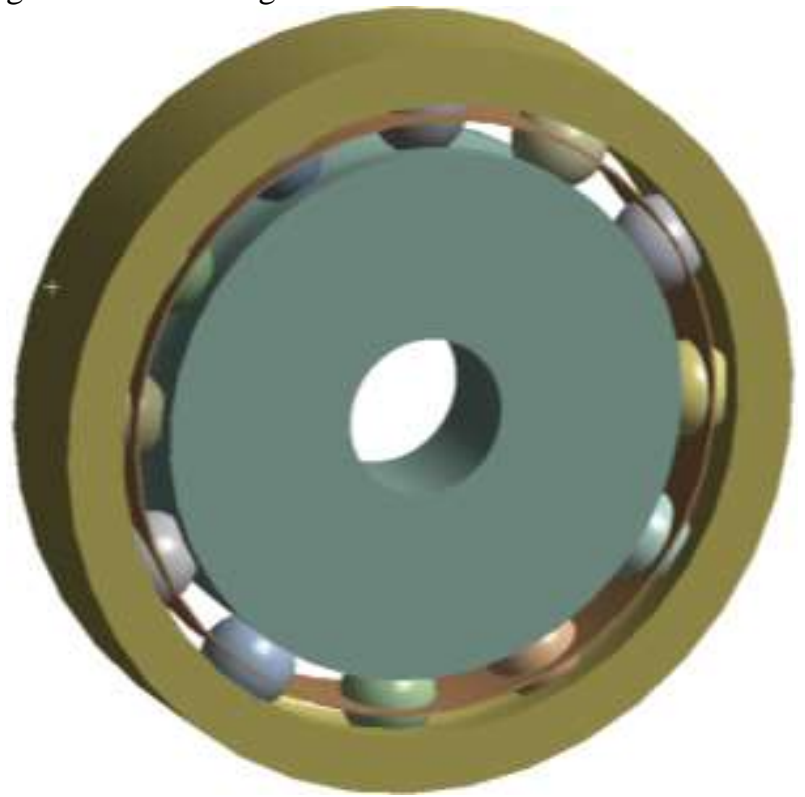

Figure 3 Three dimesional CAD model of deep groove ball bearing

The deep groove ball bearing's Computer - aided design configuration is imported through into ANSYS workbench for additional assessment, and the succeeding stage is meshing. In FEA meshing is a crucial step in which the CAD topography is broken down into a huge number of small pieces. Mesh refers to the small pieces. Figure no. 3 demonstrates the mesh generated for deep groove ball bearings in this employment. The overall number of nodes is 1158497 , and the overall number of components with tetra and hexahedral elements is 357838 .

Table 1. Higher carbon chromium steel material characteristics

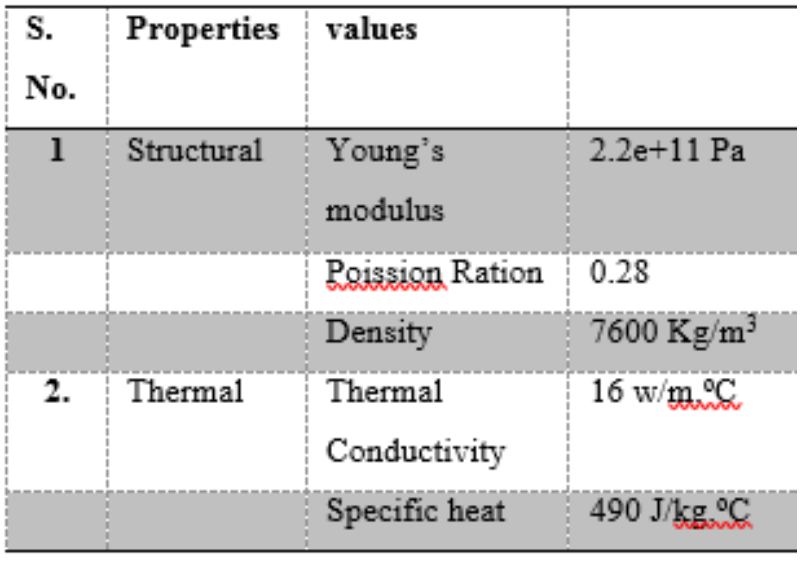

Table 2 Metal matrix composites characteristics (Ti-6Al-4 V12TiC)

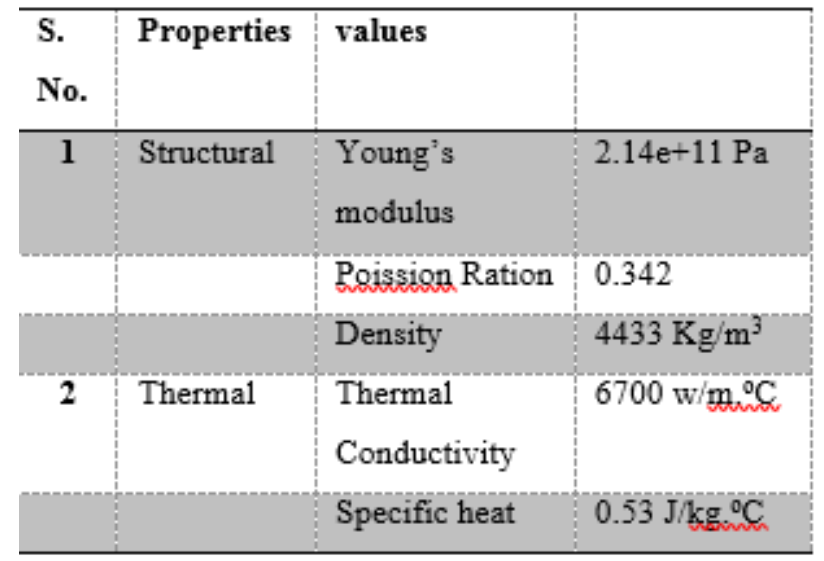

Table 3 Stainless steel material parameters

\begin{tabular}{|c|c|c|c|c|c|c|c|c|c|}
\hline $\begin{array}{c}\text { steel } \\
\text { no. }\end{array}$ & \multicolumn{7}{|c|}{ Chemical Composition \% } \\
\cline { 2 - 10 } & $\mathbf{C}$ & Si & Min & P & S & Cr & M & Cu & Ni \\
& & & & & & & o & & \\
& & & & & & & & & \\
\hline GCr & $0.95-$ & $0.15-$ & $0.25-$ & $\mathrm{s} 0.0$ & $\mathrm{~s} 0.0$ & $1.40-$ & - & $\mathrm{s} 0$. & $\mathrm{s} 0$. \\
$\mathbf{1 5}$ & 1.05 & 0.35 & 0.45 & 25 & 25 & 1.65 & & 25 & 30 \\
\hline
\end{tabular}


Table 4. Material properties of GCr15 steel

\begin{tabular}{clll}
\hline $\begin{array}{c}\text { S. } \\
\text { No. }\end{array}$ & Properties & values & \\
\hline $\mathbf{1}$ & Structural & Young's modulus & $2.07 \mathrm{e}+11 \mathrm{~Pa}$ \\
& & Poission Ration & 0.3 \\
& & Density & $7850 \mathrm{Kg} / \mathrm{m}^{3}$ \\
$\mathbf{2}$ & Thermal & Thermal & $46 \mathrm{w} / \mathrm{m}^{\circ} \mathrm{C}$ \\
& & Conductivity & \\
& & Specific heat & $470 \mathrm{~J} / \mathrm{kg} .{ }^{\circ} \mathrm{C}$ \\
& & & Miaomiao Li et el \\
& & & 2021 \\
\hline
\end{tabular}

Table 5. Material properties of silicon nitride (Si3N4)

\begin{tabular}{ccll}
\hline $\begin{array}{l}\text { S. } \\
\text { No. }\end{array}$ & Properties & values & \\
\hline $\mathbf{1}$ & Structural & $\begin{array}{l}\text { Young's } \\
\text { modulus }\end{array}$ & $3.1 \mathrm{e}+11 \mathrm{~Pa}$ \\
& & $\begin{array}{l}\text { Poission Ration } \\
\text { Density }\end{array}$ & 0.26 \\
& & $3200 \mathrm{Kg} / \mathrm{m}^{3}$ \\
$\mathbf{2}$ & Thermal & $\begin{array}{l}\text { Thermal } \\
\text { Conductivity }\end{array}$ & $319 \mathrm{w} / \mathrm{m}^{\circ} \mathrm{C}$ \\
& & Specific heat & $480 \mathrm{~J} / \mathrm{kg} .{ }^{\circ} \mathrm{C}$ \\
& & Miaomiao Li et el \\
& & & 2021 \\
& & & \\
\hline
\end{tabular}

Table 6. Material properties of Zirconium dioxide (ZrO2)

\section{S. $\quad$ Propertie values}

No. $s$

\begin{tabular}{llll}
\hline 1 & Structural & $\begin{array}{l}\text { Young's } \\
\text { modulus }\end{array}$ & $2.5 \mathrm{e}+11 \mathrm{~Pa}$ \\
& & Poission & 0.32 \\
& Ration \\
& & \\
& & Density & $6150 \mathrm{Kg} / \mathrm{m}^{3}$ \\
2 & Thermal & Thermal & $2.7 \mathrm{w} / \mathrm{m} .{ }^{\circ} \mathrm{C}$ \\
& & Conductivi \\
& ty \\
& & \\
\end{tabular}

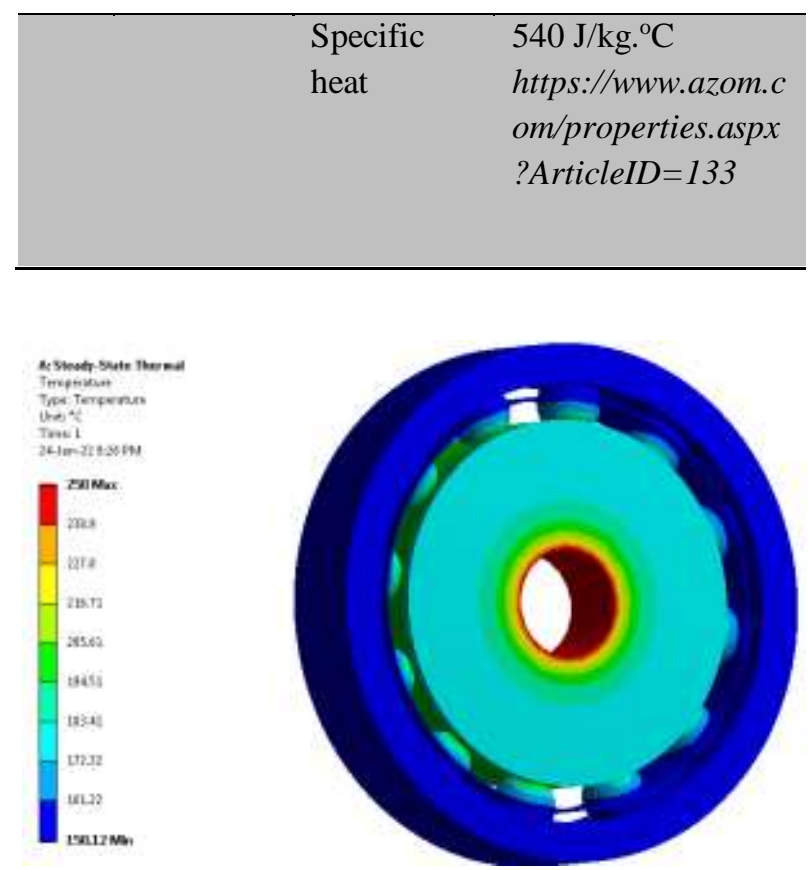

Figure 4 Temperature Distribution of Present Work
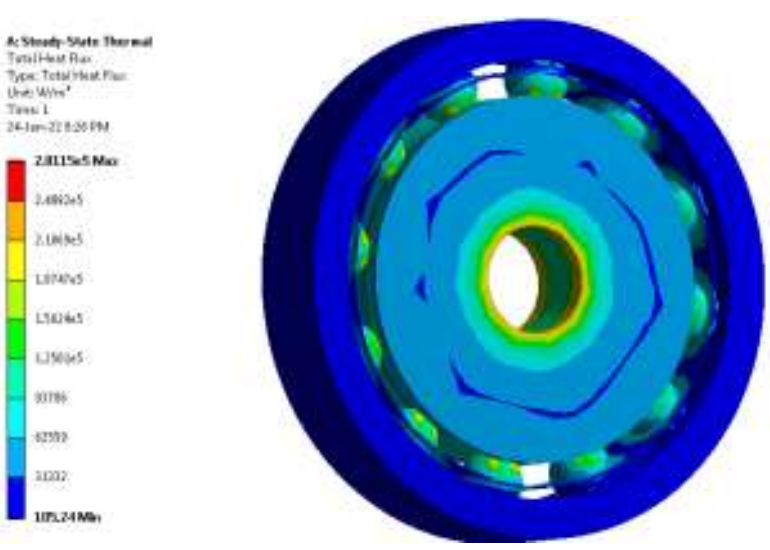

Figure 5 Overall Heat Flux 

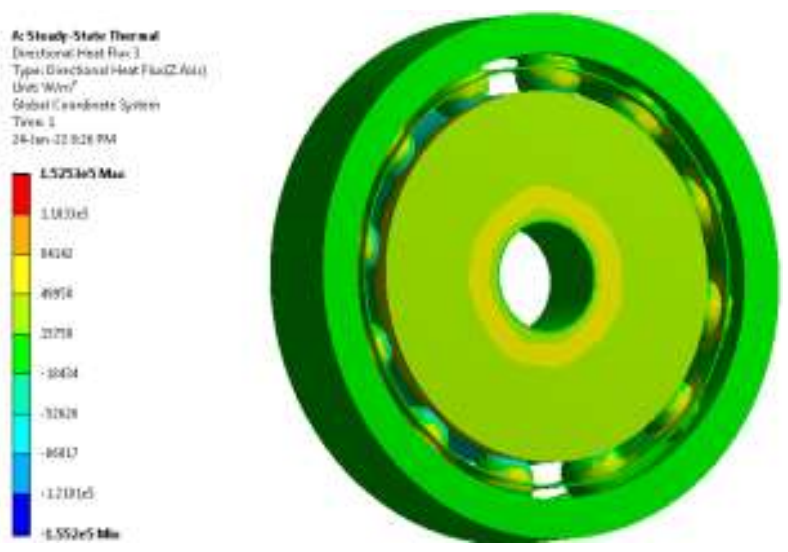

Figure 6 Directional heat flux

\begin{tabular}{lccc}
\hline Parameters & $\begin{array}{l}\text { Santhosh et } \\
\text { al. 2020 }\end{array}$ & $\begin{array}{l}\text { Present } \\
\text { work }\end{array}$ & Variation \\
\hline $\begin{array}{l}\text { Max. } \\
\text { Temperature }\end{array}$ & 250 & 250 & 0.0 \\
distribution $\left[{ }^{\circ} \mathrm{C}\right]$ & & & \\
$\begin{array}{l}\text { Total heat flux } \\
{\left[\mathrm{W} / \mathrm{m}^{2}\right]}\end{array}$ & $1.3438 \mathrm{e}+5$ & $2.8115 \mathrm{e}+5$ & $>1.09$ \\
$\begin{array}{l}\text { Directional heat } \\
\text { flux }\left[\mathrm{W} / \mathrm{m}^{2}\right]\end{array}$ & $1.037 \mathrm{e}+5$ & $1.5253 \mathrm{e}+5$ & $>0.5$ \\
\hline
\end{tabular}

\section{RESULT AND DISCUSSION}

The main goal of this study is to perform heat transfer analysis on deep grove ball bearings for different materials in order to improve thermal efficiency. A three-dimensional Computer Aided Design model of a deep groove ball bearing with an external radius of $55 \mathrm{~mm}$ and an internal radius of $35 \mathrm{~mm}$ with rolling balls with a radius of $4.7625 \mathrm{~mm}$ and 12 balls was conduct to undertake thermal assessment for stainless steel, high carbon chromium steel, metal matrix (Ti-6Al-4 V-12TiC), GCr15 steel ( $\mathrm{ZrO} 2)$. This section shows the findings of conducting thermal assessment on all of the previous section materials in the form of a contour diagram and visual presentation.
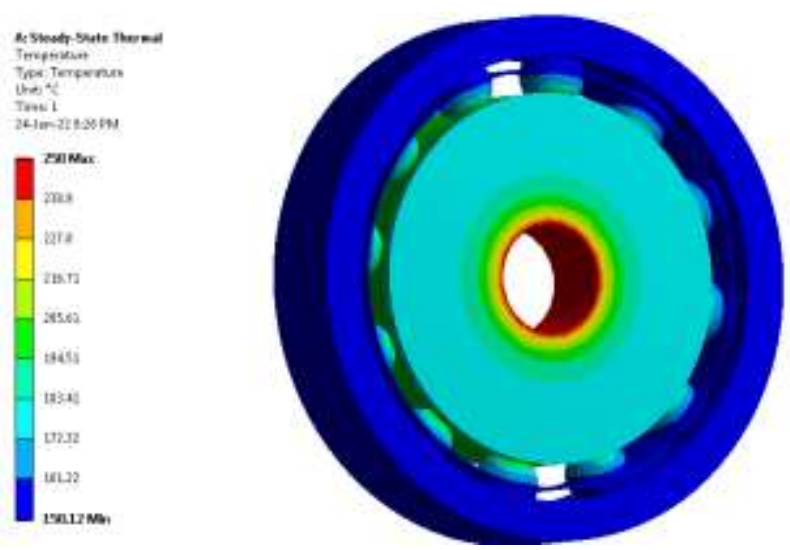

Figure 7 Stainless steel temperature difference

The temperature distribution contour was acquired upon conducting thermal assesment on stainless steel deep groove ball bearings; the highest temperature of $250 \mathrm{oC}$ was noticed at the internal part of the bearing, as can be seen in figure 7 .
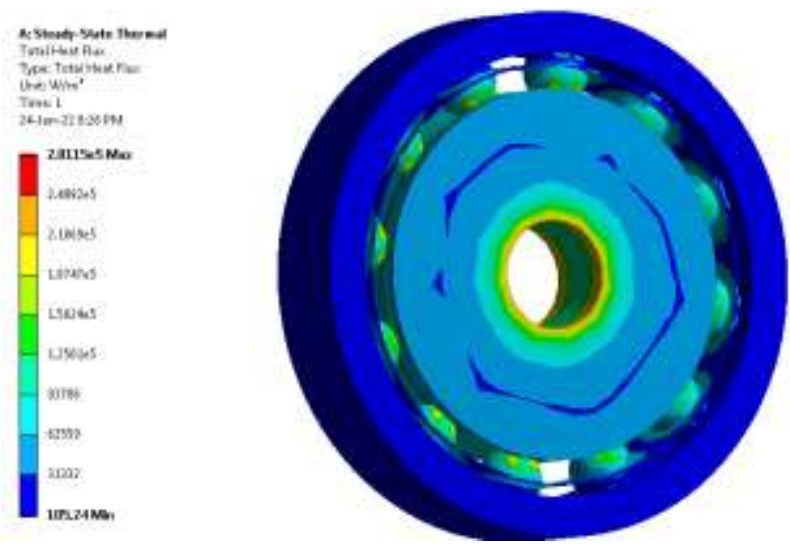

Figure 8 Overall heat flux for stainless steel

The overall heat flux contour was acquired after conducting thermal assessment on stainless steel deep groove ball bearings, and the high thermal flux of $2.8118 \mathrm{e}+5 \mathrm{w} / \mathrm{m} 2$ was identified, as can be seen in figure 8 . 

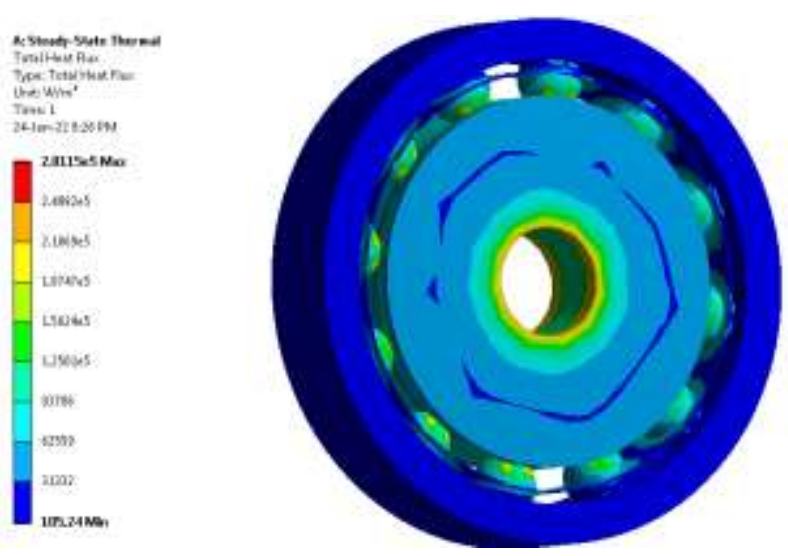

Figure 9 Total heat flux for stainless steel

The overall heat flux contour was acquired after conducting thermal analysis on stainless steel deep groove ball bearings, and the maximum heat flux of $2.8118 \mathrm{e}+5 \mathrm{w} / \mathrm{m} 2$ was noticed, as seen in the figure 9 .
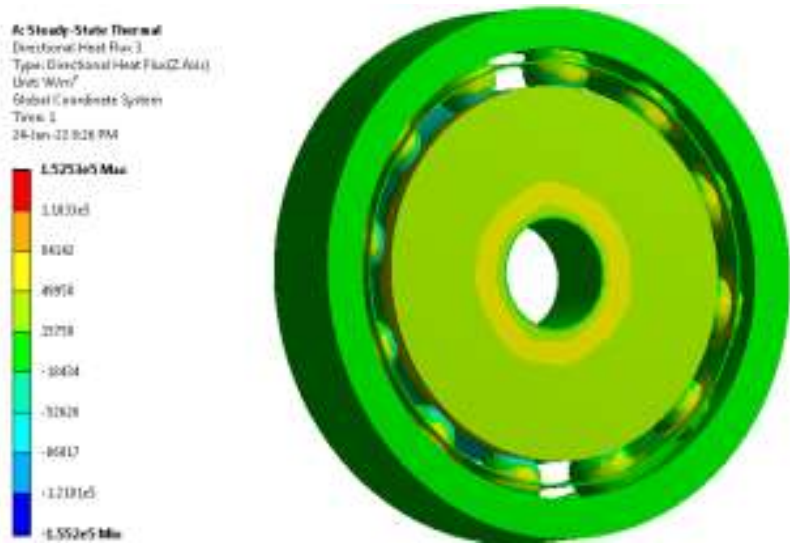

Figure 10 Directional heat flux for stainless steel

The directional heat flux contour was acquired after conducting experimental investigation on stainless steel deep groove ball bearings, and the maximum heat flux of $1.5253 \mathrm{e}+5 \mathrm{w} / \mathrm{m} 2$ was noticed, as seen in figure 10 .

\begin{tabular}{|l|c|c|c|}
\hline $\begin{array}{c}\text { Materials of } \\
\text { deep groove ball } \\
\text { bearings }\end{array}$ & $\begin{array}{c}\text { Temperatur } \\
\mathbf{e} \\
\text { distribution } \\
{[\mathbf{o C}]}\end{array}$ & $\begin{array}{c}\text { Total } \\
\text { heat flux } \\
{\left[\mathbf{w} / \mathbf{m}^{2}\right]}\end{array}$ & $\begin{array}{c}\text { Directiona } \\
\text { l heat flux } \\
{\left[\mathbf{w} / \mathbf{m}^{2}\right]}\end{array}$ \\
\hline Stainless steel & 250 & $\begin{array}{c}2.81 \mathrm{E}+0 \\
5\end{array}$ & $1.53 \mathrm{E}+05$ \\
\hline $\begin{array}{l}\text { Titanium alloy } \\
\text { Metal Matrix } \\
\text { (Ti-6Ai-4V- }\end{array}$ & 250 & $\begin{array}{c}3.68 \mathrm{E}+0 \\
5\end{array}$ & $1.92 \mathrm{E}+05$ \\
12YiC) & 250 & $7.73 \mathrm{E}+0$ & $3.50 \mathrm{E}+05$ \\
\hline
\end{tabular}

\begin{tabular}{|l|c|c|c|} 
Chromium steel & 250 & $\begin{array}{c}2.93 \mathrm{E}+0 \\
5\end{array}$ & $1.58 \mathrm{E}+05$ \\
\hline GCr15 steel & 250 & $\begin{array}{c}5.99 \mathrm{E}+0 \\
5\end{array}$ & $2.68 \mathrm{E}+05$ \\
\hline $\begin{array}{l}\text { silicon nitride } \\
\left(\mathbf{S i}_{3} \mathbf{N}_{4}\right)\end{array}$ & 250 & $\begin{array}{c}1.99 \mathrm{E}+0 \\
6\end{array}$ & $9.30 \mathrm{E}+05$ \\
\hline $\begin{array}{l}\text { Zirconium } \\
\text { dioxide }\left(\mathbf{Z r O}_{2}\right)\end{array}$ & 250 & $\begin{array}{c}1.99 \mathrm{E}+0 \\
6\end{array}$ & $9.30 \mathrm{E}+05$ \\
\hline
\end{tabular}

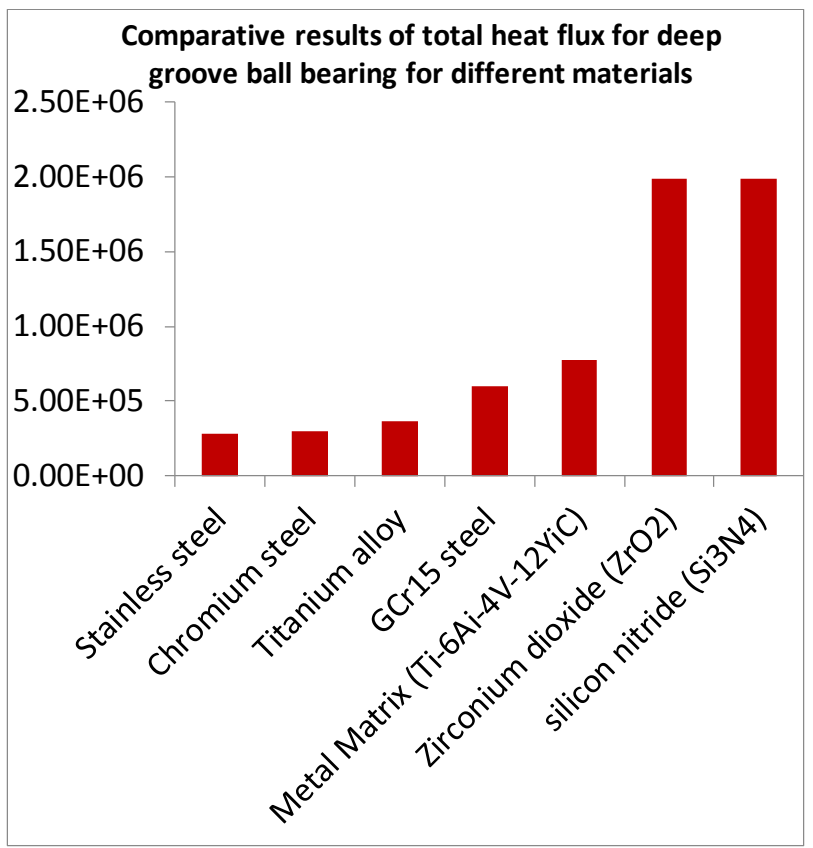

Figure 11 Comparative results of total heat flux for deep groove ball bearing for different materials

In comparison to other materials such as stainless steel, chromium steel, titanium alloy, GCr15 steel, and metal matrix, the total heat flux in deep groove ball bearings for zirconium dioxide \& silicon nitride gives better results, according to the results analysis.

Heat flux in chromium steel is 4.3 percent higher than that of stainless steel, titanium alloy is 25.34 percent higher than chromium steel, $\mathrm{CCr} 15$ is 63.015 percent higher than titanium alloy, metal matrix (Ti-6Al-4 V-12TiC) is 28.97 percent higher than GCr15 steel, and zirconium dioxide and silicon nitride is 1.57 times higher than metal matrix and other materials. 


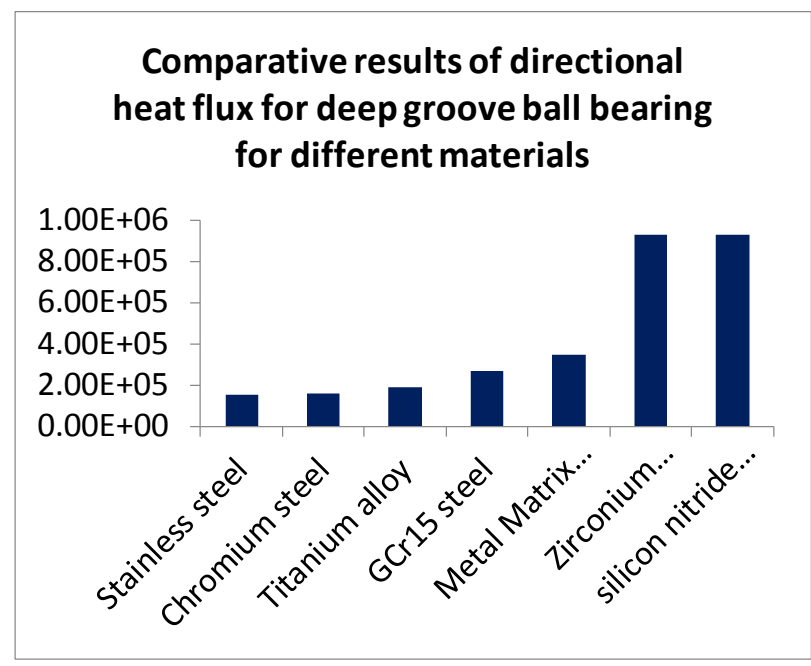

Figure 12 Comparative results of directional heat flux for deep groove ball bearing for different materials

It was also discovered that chromium steel has a 4.3 percent higher directional heat flux than stainless steel, titanium alloy has a 25.34 percent higher directional heat flux than chromium steel, CCr15 has a 63.015 percent higher directional heat flux than titanium alloy, metal matrix (Ti-6Al-4 V-12TiC) has a 28.97 percent higher directional heat flux than GCr15 steel, and zirconium dioxide and silicon nitride.

Zirconium dioxide and silicon nitride also provide 6.07 times the directional heat flux of stainless steel, 5.78 times that of chromium steel, 4.41 times that of titanium alloy, 2.32 times that of $\mathrm{CCr} 15$, and 1.57 times that of metal matrix. As a result, zirconium dioxide and silicon nitride have superior thermal properties.

\section{CONCLUSION}

From this analysis, the following are the findings.

1. The overall heat heat flux is $2.8118 \mathrm{e}+5 \mathrm{w} / \mathrm{m} 2$ and the directional heat flux is $1.5253 \mathrm{e}+5 \mathrm{w} / \mathrm{m} 2$ after conducting thermal assessment on deep groove ball bearing for stainless steel for temperature range $150 \mathrm{oC}$ to $250 \mathrm{oC}$.

2. The total heat flux is $3.6761 \mathrm{e}+5 \mathrm{w} / \mathrm{m} 2$ and the directional heat flux is $1.9182 \mathrm{e}+5 \mathrm{w} / \mathrm{m} 2$, which is 4.3 percent more than stainless steel, according to thermal assesment on deep groove ball bearings for titanium alloy in the temperature range $150 \mathrm{oC}$ to $250 \mathrm{oC}$.

3. The total heat flux is $7.7287 \mathrm{e}+5 \mathrm{w} / \mathrm{m} 2 \mathrm{w} / \mathrm{m} 2$ and the directional heat flux is $3.5015 \mathrm{e}+5 \mathrm{w} / \mathrm{m} 2$, which is 63.015 percent more than titanium alloy, according to thermal analysis on deep groove ball bearing for Metal Matrix (Ti-6Ai-4V-12YiC) for temperature range $150 \mathrm{oC}$ to $250 \mathrm{oC}$.
4. The total heat flux is $2.9328 \mathrm{e}+5 \mathrm{w} / \mathrm{m} 2 \mathrm{w} / \mathrm{m} 2$ and the directional heat flux is $1.5849 \mathrm{e}+5 \mathrm{w} / \mathrm{m} 2$, which is 63.015 percent more than titanium alloy after thermal analysis on deep groove ball bearing for chromium steel for temperature range $150 \mathrm{oC}$ to 250 oC.

5. The overall heat flux is $5.9926 \mathrm{e}+5 \mathrm{w} / \mathrm{m} 2 \mathrm{w} / \mathrm{m} 2$ and the directional heat flux is $2.6831 \mathrm{e}+5 \mathrm{w} / \mathrm{m} 2$, which really is 25.34 percent further than chromium steel, according to thermal assessment on deep groove ball bearing for $\mathrm{GCr} 15$ steel for temperature range $150 \mathrm{oC}$ to $250 \mathrm{oC}$.

6. The overall heat flux is $1.9907 \mathrm{e}+6 \mathrm{w} / \mathrm{m} 2 \mathrm{w} / \mathrm{m} 2$ and the directional heat flux is $9.3037 \mathrm{e}+5 \mathrm{w} / \mathrm{m} 2$ after thermal assessment on deep groove ball bearing for Silicon nitride (Si3N4) for temperature range $150 \mathrm{oC}$ to $250 \mathrm{oC}$, which is 28.97 percent further than $\mathrm{GCr} 15$ steel.

Heat flux in chromium steel is 4.3 percent higher than stainless steel, titanium alloy is 25.34 percent higher than chromium steel, CCr15 is 63.015 percent higher than titanium alloy, metal matrix (Ti-6Al-4 V-12TiC) is 28.97 percent higher than GCr15 steel, and zirconium dioxide and silicon nitride is 1.57 times higher than metal matrix and other components, according this conclusion. Zirconium dioxide and silicon nitride also provide 6.07 times the total heat flux of stainless steel, 5.78 times that of chromium steel, 4.41 times that of titanium alloy, 2.32 times that of $\mathrm{CCr} 15$, and 1.57 times that of metal matrix. As a result, zirconium dioxide and silicon nitride have superior thermal properties.

\section{References}

[1] Dinh Sy Truong et al. (2021) "An analysis of a thermally affected high-speed spindle with angular contact ball bearings" Tribology International 157 (2021)

106881https://doi.org/10.1016/j.triboint.2021.106881

[2] Miaomiao Li et al. (2021) "Temperature rise characteristics for angular-contact ball bearings with oil-air lubrication based on fluid-solid conjugate heat transfer" Advances in Mechanical Engineering 2021, Vol. 13(1) 1-13 DOI: 10.1177/1687814021990927

[3] Shuai Gao et al. (2021) "Ball bearing skidding and over-skidding in large-scale angular contact ball bearings: Nonlinear dynamic model with thermal effects and experimental results" Mechanical Systems $\begin{array}{lllll}\text { and Signal Processing } 147 & \text { (2021) } & 107120\end{array}$ https://doi.org/10.1016/j.ymssp.2020.107120

[4] V. Choubey \& S. Agarwal (2021) "Heat Transfer Analysis of Ball Bearing for three different materials using ANSYS" European Journal of Advances in 
Engineering and Technology, 2021, 8(6):20-25 ISSN: $2394-658 X$

[5] P.C. Santhosh Kumar et al (2020) "Heat transfer analysis for different materials of ball bearing using ANSYS"

(2020)

https://doi.org/10.1016/j.matpr.2020.10.944

[6] Jialan Liu et al. (2020) "Thermal contact conductance between balls and bearing rings" International Communications in Heat and Mass Transfer 117 (2020) 104780

https://doi.org/10.1016/j.icheatmasstransfer.2020.1047 80.

[7] $\mathrm{Yu}$ Wang et al (2020) "Study on the Thermal Performance and Temperature Distribution of Ball Bearings in the Traction Motor of a High-Speed EMU" applied sciences 2020, 10, 4373; doi:10.3390/app10124373.

[8] Bei Yan et al. (2019) "Thermal coefficients modification of high speed ball bearing by multi-object optimization method" International Journal of Thermal $\begin{array}{llll}\text { Sciences } & 137 & \text { (2019) } & 313-324\end{array}$ https://doi.org/10.1016/j.ijthermalsci.2018.11.027

[9] Dinh Sy Truong et al. (2019) "Thermally affected stiffness matrixof angular contact ball bearings in a high-speed spindle system" Advances in Mechanical Engineering 2019, Vol. 11(11) 1-17 https://us.sagepub.com/en-us/nam/open-access-at-sage

[10]G. Srinubabu\& K. Muralidhar (2019) "Design and Thermal Analysis of Ball Bearing using Various Materials on Finite Element Method" International Journal of Applied Sciences, Engineering and Management ISSN 2320 - 3439, Vol. 08, No. 05, September 2019, pp. 06-11

[11]Clement Rabreau et al (2018) "Influence of bearing kinematics hypotheses on ball bearing heat generation" Procedia CIRP 77 (2018) 622-625 https://hal.archivesouvertes.fr/hal-02012335

[12] Xianwen Zhou et al. (2018) "Investigation on thermal behavior and temperature distribution of bearing inner and outer rings. Tribology" International (2018), doi: https://doi.org/10.1016/j.triboint.2018.09.031.

[13] Abdullah Jamil et al. (2018) "Mathematical Modelling and Transient Thermal Analysis of Coupler-Rocker Bearing" UTP-UMP-VIT SES 2018, MATEC Web of Conferences 225, $04005 \quad$ (2018) https://doi.org/10.1051/matecconf/201822504005.
[14] Junning Li et al. (2018) "Study on the Thermal Distribution Characteristics of High-Speed and LightLoad Rolling Bearing Considering Skidding" Appl. Sci. 2018, 8, 1593; doi:10.3390/app8091593 www.mdpi.com/journal/applsci.

[15] Xiaoping Li et al. (2018) "Analysis for Thermal Characteristics of High-Speed Angular Contact Ball Bearing under Different Preload" Advances in Computer Science Research, volume 83. 8th International Conference on Social Network, Communication and Education (SNCE 2018 pp 429433. 